\title{
Novel SPECT perfusion imaging agents with improved myocardial or liver kinetics: Experimental studies and the need for clinical evaluation
}

\author{
Laurent M. Riou, $\mathrm{PhD},{ }^{\mathrm{a}, \mathrm{b}}$ and Alexis Broisat, $\mathrm{PhD}^{\mathrm{a}, \mathrm{b}}$
}

\section{See related article, pp. 858-867}

Myocardial nuclear perfusion imaging represents the most extensively used non-invasive diagnostic and prognostic tool for coronary artery disease. As reviewed in an excellent editorial by Dahlberg, ${ }^{1}$ the suboptimal physical characteristics of the historical agent Tl-201 have prompted the development of Tc-99 m-labeled myocardial perfusion imaging agents with more favorable emission energy and dosimetry. For a number of reasons that were addressed in the abovementioned editorial, and despite excellent myocardial extraction and encouraging clinical results, the neutral and lipophilic tracers TcN-NOET and Tc-TEBOROXIME have not reached routine clinical use. ${ }^{1}$ On the other hand, the cationic and lipophilic tracer Tc-MIBI has been extensively studied experimentally ${ }^{2-10}$ and has reached wide clinical acceptance for a number of years. However, in addition to suboptimal myocardial extraction in comparison to that of Tl-201 due to the roll-off phenomenon leading to underestimation of myocardial perfusion at high flow rates, ${ }^{7}$ Tc-MIBI also presents a modest heartto-liver activity ratio which is comparable or lower than that of Tl-201 and which might be responsible for misinterpretation of myocardial perfusion in the inferior or inferoapical left ventricular wall. ${ }^{11,12}$ In the clinical setting however, despite these different biological, physical, and imaging characteristics, both Tl-201 and Tc-MIBI have comparable diagnostic accuracies for detecting coronary artery disease, as confirmed in the

From the INSERM, U877 Radiopharmaceutiques Biocliniques ${ }^{\mathrm{a}}$ and Université de Grenoble I, ${ }^{\mathrm{b}}$ Grenoble, France.

Reprint requests: Laurent M. Riou, PhD, INSERM, U877 Radiopharmaceutiques Biocliniques, Grenoble, France; Laurent.Riou@ujfgrenoble.fr.

J Nucl Cardiol 2010;17:771-4.

$1071-3581 / \$ 34.00$

Copyright (c) 2010 American Society of Nuclear Cardiology.

doi:10.1007/s12350-010-9275-6 large randomized ROBUST study. ${ }^{12}$ Similarly, the prognostic power of nuclear perfusion imaging-i.e., its ability for predicting future coronary events-has been demonstrated in a large number of high-quality studies and in thousands of patients, whatever the tracer used. ${ }^{13}$

Tc-TETROFOSMIN is another cationic and lipophilic tracer of myocardial perfusion that was approved for clinical use 6 years after Tc-MIBI. The cellular uptake mechanisms of both tracers consist in mitochondrial accumulation due to the negative mitochondrial membrane potential and the positive charge associated with the lipophilicity of the tracers. Although Tc-TETROFOSMIN presents a flow-extraction curve similar to that of Tc-MIBI, ${ }^{14}$ the heart-to-liver ratio of the tracer turned out to be significantly higher than that of Tc-MIBI in the clinical setting. ${ }^{15}$ The more favorable liver kinetics of Tc-TETROFOSMIN resulted in a lower number of poor quality scans than observed with Tc-MIBI in daily practice, ${ }^{16}$ a result which however did not lead to differences in sensitivity, specificity, and diagnostic accuracy between the two tracers. ${ }^{17}$

As described below, a number of experimental studies including the paper by Liu et $\mathrm{al}^{18}$ in this issue of the Journal have addressed the issue of developing new myocardial perfusion imaging agents with improved myocardial and/or liver kinetics in comparison with those of Tc-MIBI. Although these studies often yielded encouraging experimental results, the current literature clearly lacks clinical data confirming the improved kinetics of these novel agents over Tc-MIBI.

$7^{\prime}$-Z-[125I]-iodorotenone (ZIROT) is a neutral and lipophilic inhibitor (IC50 $=0.25 \mathrm{nmol} / \mathrm{L}$ ) of complex I of the mitochondrial transport electron chain. Biodistribution experiments in rodents indicated that ZIROT heart-to-liver ratio was significantly higher than that of Tc-MIBI and similar to that of Tc-TETROFOSMIN. ${ }^{19}$ Experiments performed on isolated, erythrocytes-, and albumin-perfused rabbit hearts indicated a much higher extraction of ZIROT $(84 \pm 5 \%)$ when compared with that of Tc-MIBI $(48 \pm 10 \%){ }^{20}$ The superiority of ZIROT flow vs extraction relationship over Tc-MIBI was confirmed in a canine model of critical coronary 
stenosis, ${ }^{21}$ in which ZIROT also outperformed the values of Thallium-201 myocardial extraction as measured previously in similar experimental conditions. Interestingly, a $\left[{ }^{18} \mathrm{~F}\right]$-labeled rotenone also demonstrated an initial extraction fraction similar to that of Thallium-201 in isolated, erythrocytes-, and albumin-perfused rabbit hearts. ${ }^{22}$ Despite these experimental results suggesting that the excellent extraction fraction of radiolabeled rotenone may provide a mean for the absolute quantification of myocardial blood flow, no clinical data are yet available with such tracers. This situation may possibly be due to the need for iodine radiolabeling as far as SPECT imaging is concerned.

The agents Tc-N-MPO, Tc-15C5PNP, and Tc-DBODC5 mentioned below belong to a class of cationic perfusion imaging agents composed of two different bidentate ligands that have been synthesized in order to optimize the balance between myocardial extraction and liver uptake. ${ }^{23}$ Along the same line, it should be mentioned that Bolzati et $\mathrm{al}^{24}$ recently published the synthesis and biological evaluation of a new series of bidentate ligands from which two potentially promising candidates have been selected for further experimental evaluation.

Tc-N-MPO is a mono-cationic tracer that accumulates in the mitochondrial fraction to the same extent as Tc-MIBI as demonstrated by a myocardial subcellular distribution study following intravenous injection of the tracers to rats. ${ }^{25}$ Biodistribution experiments performed in the same experimental model indicated that Tc-99 m-N-MPO heart-to-liver ratio was much higher than that of Tc-MIBI at all time points, and slightly and transiently higher than that of the novel perfusion imaging agent Tc-DBODC5 (see below). ${ }^{26}$ The likely mechanism for fast liver clearance of Tc-N-MPO in rats is an efficient recognition of the tracer by the MDR transport function of hepatocytes. ${ }^{25}$ Additional studies in guinea pigs led to somewhat disappointing results with similar Tc-N-MPO and Tc-MIBI myocardial and liver activities resulting in a modest and transiently significant advantage of $\mathrm{Tc}-\mathrm{N}$ MPO over Tc-MIBI with respect to heart-to-liver ratio. ${ }^{26}$ Finally, a recent study indicated a heart-to-liver ratio of $1.2 \pm 0.1$ in a canine model. ${ }^{27}$ Again, no clinical data are yet available regarding the myocardial and liver kinetics of Tc-N-MPO in patients.

In this issue of the Journal, Liu et al ${ }^{18}$ performed experimental cardiac imaging in rats using the cationic tracer Tc-15C5-PNP and compared the results with those obtained using Tc-MIBI. He et $\mathrm{al}^{28}$ initially described the biodistribution of Tc-15C5-PNP in 2006. Surprisingly, the heart-to-liver ratios that were obtained from biodistribution experiments by $\mathrm{He}$ et al were significantly higher than those observed by Liu et al despite similar experimental conditions $(9.5 \pm 3.0$ vs $3.3 \pm 0.3$ at 60 minutes post-tracer injection, respectively). In any case, in vivo SPECT acquisitions revealed perfusion images of similar quality with both tracers and an objectively lower liver activity when using Tc-15C5PNP as compared with Tc-MIBI.

Finally, Tc-DBODC5 probably is the agent that has undergone the most extensive experimental evaluation. Biodistribution studies in rats indicated an excellent heart-to-liver ratio for Tc-DBODC5 of $18.4 \pm 2.0$ at 60 minutes post-injection to be compared with values of

Table 1. Experimental and clinical heart-to-liver ratios of clinically used and currently evaluated myocardial perfusion imaging agents

\begin{tabular}{lccc}
\hline & \multicolumn{3}{c}{ Heart-to-liver ratio } \\
\cline { 2 - 4 } \multicolumn{1}{c}{ Tracer } & Experimental & \multicolumn{2}{c}{ Clinical } \\
\cline { 3 - 4 } \multicolumn{1}{c}{ Rest } & Exercise/stress \\
\hline Tc-MIBI & $2.6 \pm 0.2^{29}$ & $0.6 \pm 0.1^{11}$ & $1.8 \pm 0.3^{11}$ \\
Tc-MIBI (guinea pig) & $3.8 \pm 0.4^{26}$ & $0.6 \pm 0.1^{11}$ & $1.8 \pm 0.3^{11}$ \\
Tc-TETROFOSMIN & $5.8 \pm 0.7^{29}$ & $1.2 \pm 0.8^{15}$ & $3.1 \pm 3.0^{15}$ \\
Tc-DBODC5 & $18.4 \pm 2.0^{29}$ & $0.7 \pm 0.1^{31}$ & $1.3 \pm 0.3^{31}$ \\
Tc-N-MPO & $24.3 \pm 4.9^{26}$ & $\mathrm{~N} / \mathrm{A}$ & $\mathrm{N} / \mathrm{A}$ \\
Tc-N-MPO (guinea pig) & $5.4 \pm 0.7^{26}$ & $\mathrm{~N} / \mathrm{A}$ & $\mathrm{N} / \mathrm{A}$ \\
Tc-N-MPO (dog) & $1.2 \pm 0.1^{27}$ & $\mathrm{~N} / \mathrm{A}$ & $\mathrm{N} / \mathrm{A}$ \\
Tc-15C5PNP & $3.3 \pm 0.3^{18}$ & $\mathrm{~N} / \mathrm{A}$ & $\mathrm{N} / \mathrm{A}$ \\
ZIROT & $2.4 \pm 0.2^{19}$ & $\mathrm{~N} / \mathrm{A}$ & $\mathrm{N} / \mathrm{A}$ \\
& & &
\end{tabular}

Experimental and clinical values were determined at 60 minutes post-tracer injection.

Experimental heart-to-liver ratios were obtained from biodistribution experiments in rats otherwise indicated.

References are superscripted. 
$5.8 \pm 0.7$ and $2.6 \pm 0.2$ for Tc-TETROFOSMIN and Tc-MIBI, respectively. ${ }^{29}$ Canine studies also demonstrated an advantage for Tc-DBODC5 over Tc-MIBI with regards to heart-to-liver ratio, but to a lesser extent than that observed in rodent experiments. ${ }^{30}$ Results from a phase I clinical study are available for Tc-DBODC5. ${ }^{31}$ The heart-to-liver ratio from patients injected with the tracer reached approximately 0.7 and 1.3 under rest and stress conditions, respectively. These values are similar to those that were observed in Tc-MIBI phase I clinical study, ${ }^{11}$ and slightly lower than those observed for Tc-TETROFOSMIN ${ }^{15}$ The above data are summarized in Table 1.

In conclusion, a number of tracers with improved myocardial and/or liver kinetics have been evaluated experimentally over the last years with the aim of enhancing the quality of perfusion images currently acquired using Tc-MIBI or Tc-TETROFOSMIN. The only phase I clinical study performed using Tc-DBODC5 failed to reproduce the encouraging experimental results that were initially observed with the tracer. The clinical evaluation of experimentally validated novel perfusion imaging agents is therefore promptly needed to determine whether or not the favorable results observed in the experimental setting will translate into improved clinical kinetics.

\section{References}

1. Dahlberg ST. Assessment of myocardial perfusion with Tc-99 m: Image is everything. J Nucl Cardiol 2009;16:493-6.

2. Ruiz M, Takehana K, Petruzella FD, Watson DD, Beller GA, Glover DK. Arbutamine stress perfusion imaging in dogs with critical coronary artery stenoses: $(99 \mathrm{~m}) \mathrm{Tc}$-sestamibi versus (201)Tl. J Nucl Med 2002;43:664-70.

3. Takehana K, Ruiz M, Petruzella FD, Watson DD, Beller GA, Glover DK. Tc-99 m sestamibi defect magnitude predicts the amount of viable myocardium after coronary reperfusion despite the presence of severe residual stenosis. J Nucl Cardiol 2001;8: 40-8.

4. Calnon DA, Glover DK, Beller GA, Vanzetto G, Smith WH, Watson DD, et al. Effects of dobutamine stress on myocardial blood flow, $99 \mathrm{mTc}$ sestamibi uptake, and systolic wall thickening in the presence of coronary artery stenoses: Implications for dobutamine stress testing. Circulation 1997;96:2353-60.

5. Sansoy V, Glover DK, Watson DD, Ruiz M, Smith WH, Simanis JP, et al. Comparison of thallium-201 resting redistribution with technetium-99 m-sestamibi uptake and functional response to dobutamine for assessment of myocardial viability. Circulation 1995;92:994-1004.

6. Okada RD, Glover DK, Nguyen KN, Johnson G III. Technetium$99 \mathrm{~m}$ sestamibi kinetics in reperfused canine myocardium. Eur J Nucl Med 1995;22:600-7.

7. Glover DK, Ruiz M, Edwards NC, Cunningham M, Simanis JP, Smith WH, et al. Comparison between 201Tl and $99 \mathrm{mTc}$ sestamibi uptake during adenosine-induced vasodilation as a function of coronary stenosis severity. Circulation 1995;91: 813-20.
8. Beller GA, Glover DK, Edwards NC, Ruiz M, Simanis JP, Watson DD. $99 \mathrm{mTc}$-sestamibi uptake and retention during myocardial ischemia and reperfusion. Circulation 1993;87:2033-42.

9. Glover DK, Okada RD. Myocardial technetium $99 \mathrm{~m}$ sestamibi kinetics after reperfusion in a canine model. Am Heart $\mathrm{J}$ 1993;125:657-66.

10. Glover DK, Okada RD. Myocardial kinetics of Tc-MIBI in canine myocardium after dipyridamole. Circulation 1990;81:628-37.

11. Wackers FJ, Berman DS, Maddahi J, Watson DD, Beller GA, Strauss HW, et al. Technetium-99 m hexakis 2-methoxyisobutyl isonitrile: Human biodistribution, dosimetry, safety, and preliminary comparison to thallium-201 for myocardial perfusion imaging. J Nucl Med 1989;30:301-11.

12. Kapur A, Latus KA, Davies G, Dhawan RT, Eastick S, Jarritt PH, et al. A comparison of three radionuclide myocardial perfusion tracers in clinical practice: The ROBUST study. Eur J Nucl Med Mol Imaging 2002;29:1608-16.

13. Underwood SR, Anagnostopoulos C, Cerqueira M, Ell PJ, Flint EJ, Harbinson M, et al. Myocardial perfusion scintigraphy: The evidence. Eur J Nucl Med Mol Imaging 2004;31:261-91.

14. Glover DK, Ruiz M, Yang JY, Smith WH, Watson DD, Beller GA. Myocardial $99 \mathrm{mTc}$-tetrofosmin uptake during adenosine-induced vasodilatation with either a critical or mild coronary stenosis: Comparison with $201 \mathrm{Tl}$ and regional myocardial blood flow. Circulation 1997;96:2332-8.

15. Higley B, Smith FW, Smith T, Gemmell HG, Das Gupta P, Gvozdanovic DV, et al. Technetium-99 m-1, 2-bis[bis(2-ethoxyethyl) phosphino]ethane: Human biodistribution, dosimetry and safety of a new myocardial perfusion imaging agent. J Nucl Med 1993;34:30-8.

16. Hambÿe AS, Delsarte P, Vervaet AM. Influence of the different biokinetics of sestamibi and tetrofosmin on the interpretation of myocardial perfusion imaging in daily practice. Nucl Med Commun 2007;28:383-90.

17. Acampa W, Cuocolo A, Sullo P, Varrone A, Nicolai E, Pace L, et al. Direct comparison of technetium $99 \mathrm{~m}$-sestamibi and technetium $99 \mathrm{~m}$-tetrofosmin cardiac single photon emission computed tomography in patients with coronary artery disease. J Nucl Cardiol 1998;5:265-74.

18. Liu Z, Chen L, Liu S, Barber C, Stevenson GD, Furenlid LR, et al. Kinetic characterization of a novel cationic ${ }^{99 \mathrm{~m}} \mathrm{Tc}(\mathrm{I})$-tricarbonyl complex, ${ }^{99 \mathrm{~m}} \mathrm{Tc}-15 \mathrm{C} 5-\mathrm{PNP}$, for myocardial perfusion imaging. J Nucl Cardiol 2010. doi:10.1007/s12350-010-9262-y

19. VanBrocklin HF, Hanrahan SM, Enas JD, Nandanan E, O'Neil JP. Mitochondrial avid radioprobes. Preparation and evaluation of $7^{\prime}(\mathrm{Z})$-[125I]iodorotenone and $7^{\prime}(\mathrm{Z})$-[125I]iodorotenol. Nucl Med Biol 2007;34:109-16.

20. Marshall RC, Powers-Risius P, Reutter BW, Taylor SE, VanBrocklin HF, Huesman RH, et al. Kinetic analysis of 125Iiodorotenone as a deposited myocardial flow tracer: Comparison with 99 mTc-sestamibi. J Nucl Med 2001;42:272-81.

21. Broisat A, Ruiz M, VanBrocklin HF, Goodman NC, Hanrahan SM, Janabi M, et al. Myocardial uptake of $7^{\prime}(Z)$-[123I]iodorotenone during vasodilator stress in dogs with coronary stenoses. Circulation. 2007;116:II_659.

22. Marshall RC, Powers-Risius P, Reutter BW, O’Neil JP, La Belle $\mathrm{M}$, Huesman RH, et al. Kinetic analysis of $18 \mathrm{~F}$-fluorodihydrorotenone as a deposited myocardial flow tracer: Comparison to 201Tl. J Nucl Med 2004;45:1950-9.

23. Kim YS, He Z, Hsieh WY, Liu S. Impact of bidentate chelators on lipophilicity, stability, and biodistribution characteristics of cationic 99 mTc-nitrido complexes. Bioconjug Chem 2007;18:929-36.

24. Bolzati C, Cavazza-Ceccato M, Agostini S, Refosco F, Yamamichi $\mathrm{Y}$, Tokunaga $\mathrm{S}$, et al. Biological in vitro and in vivo studies of a 
series of new asymmetrical cationic [99mTc(N)(DTC-Ln)(PNP)]+ complex (DTC-Ln = alicyclic dithiocarbamate and PNP = diphosphinoamine). Bioconjug Chem 2010;21:928-39.

25. Kim YS, Shi J, Zhai S, Hou G, Liu S. Mechanism for myocardial localization and rapid liver clearance of Tc-99m-N-MPO: A new perfusion radiotracer for heart imaging. J Nucl Cardiol 2009;16: 571-9.

26. Kim YS, Wang J, Broisat A, Glover DK, Liu S. Tc-99m-N-MPO: Novel cationic Tc-99m radiotracer for myocardial perfusion imaging. J Nucl Cardiol 2008;15:535-46.

27. Bu L, Li R, Jin Z, Wen X, Liu S, Yang B, et al. Evaluation of (99) (m)TcN-MPO as a new myocardial perfusion imaging agent in normal dogs and in an acute myocardial infarction canine model: Comparison with (99) (m)Tc-Sestamibi. Mol Imaging Biol 2010 [Epub ahead of print].
28. He Z, Hsieh WY, Kim YS, Liu S. Evaluation of novel cationic $99 \mathrm{mTc}(\mathrm{I})$-tricarbonyl complexes as potential radiotracers for myocardial perfusion imaging. Nucl Med Biol 2006;33:1045-53.

29. Hatada K, Riou LM, Ruiz M, Yamamichi Y, Duatti A, Lima RL, et al. 99mTc-N-DBODC5, a new myocardial perfusion imaging agent with rapid liver clearance: Comparison with $99 \mathrm{mTc}$-sestamibi and 99mTc-tetrofosmin in rats. J Nucl Med 2004;45:2095-101.

30. Hatada K, Ruiz M, Riou LM, Lima RL, Goode AR, Watson DD, et al. Organ biodistribution and myocardial uptake, washout, and redistribution kinetics of Tc-99m N-DBODC5 when injected during vasodilator stress in canine models of coronary stenoses. J Nucl Cardiol 2006;13:779-90.

31. Cittanti C, Uccelli L, Pasquali M, Boschi A, Flammia C, Bagatin E, et al. Whole-body biodistribution and radiation dosimetry of the new cardiac tracer 99mTc-N-DBODC. J Nucl Med 2008;49:1299-304. 